\title{
Star Architects, Urban Spectacles and Global Brands: Exploring the Case of the Tokyo Olympics 2020
}

\begin{abstract}
Olympic stadia are often regarded as a political showcase involving a range of influences: the host nation's international politics, the interests of transnational capitalism along with site-specific meanings and the power of iconic architecture. By examining the 2020 Tokyo Olympic main stadium as a case study, the paper analyzes the controversial Zaha Hadid' stadium plan in relation to the Japanese nation branding initiative. In doing so, the paper argues that 'branding' should be seen as part of an economic and cultural system which seems to enhance the global value of iconic architects and their buildings. Yet, the power of brands can be understood as a contingent entity. This is because its ambivalenct nature entails a tension between exclusiveness and banality; additionally, it could be difficult for branded architects to work across the different regimes of global and local politics; and they are of course also constrained by the logic of neoliberal transnational capitalism. By investigating a major global branded architect, Zaha Hadid and her architecture plan, the paper considers why a new image of Japan could not be adequately created by Hadid's aesthetics and narratives of the Olympic stadium which should be regarded as a national cultural legacy. The paper then discusses the contested processes of image-making and narrative creation in relation to the representation of Japan in contemporary Olympic culture. The paper concludes with an examination of Kengo Kuma's architecture language in his 2020 Tokyo Olympics stadium design.
\end{abstract}

Keyword: architecture, Olympics, brand, neoliberalism, social media, Tokyo 


\section{Introduction}

It is generally accepted that the Olympics are a juxtaposition that comprises of a human-made spectacle, nation branding, and city planning at one and the same time. It is also a contested field of sovereignty, which is often regarded as entailing a series of power balances between political (e.g. government), economic entities (e.g. global capitalism) and citizens.

The paper focuses on iconic architecture and architects in the context of Olympic culture. The Olympic stadia could be seen as one of the most noticeable Olympic facilities, since they often appear as iconic buildings designed by star architects. Therefore, they play a significant role on the global stage to create great opportunities for hosting nations to promote a favourable image in order to promote their place in the global hierarchy. The increasing tendency to build and utilize emblematic architecture for Olympic stadia does not only materializes the aforementioned immanent features of the global mega events, but also can been seen as an ideal site for exploring the material and symbolic processes of iconic architecture in the era of global capitalism.

Taking the 2020 Tokyo Olympic stadium as a case study, the paper unpacks the relationship between the material and symbolical infrastructure of iconic architecture, which involves political interests, economic capital and sitespecific memories. Rather than focusing on various critical issues: such as the massive budgets for 'white elephant' Olympic stadia; analysing detail of architecture designs; criticising the process of the design competition; or problematising related political issues in the Japanese architectural industry, all of which has already been extensively discussed, the paper investigates the socio-cultural implications of the iconic Olympic stadium designed by a globally branded star architect.

By doing so, the paper conceptualises 'branding' as an economic and cultural system, which works to incorporate 'a new set of symbolic values' into iconic 
buildings and star architects. The paper also examines the shifting and multifaceted identities of the iconic architects and the 'commodification' and 'narrativization' of branded star architects and architecture.

Finally, the paper argues that despite the branding system instituting a new assemblage of dominant symbolic value to iconic buildings and star architects, the power of brand can be understood as a contingent entity in terms of its ambivalent nature and tension between exclusiveness and banality in global cultural capitalism. The paper then claims that given such complex environments, the global branded architect, Zaha Hadid's aesthetics and narratives for the Olympic stadium failed to provide an adequate representative new image of Japan to relate to Japanese national culture and legacy.

The paper concludes with an examination of the architecture language of Kengo Kuma in his 2020 Tokyo Olympics stadium design.

\section{Architecture as a contested political site}

Today we find that iconic architecture not only works to provide expressions of national identity and inventing narratives of tradition, but also become a contested political site between state, global capitalists, iconic architecture and citizens. As linked to expanding global capitalism and the flow of financial power, the increasing political and economic influence of iconic architecture as 'a heteronomous practice' (McNeill 2009:3), makes it become a rather complex powerhouse. McNeill emphases 'the importance of "heteronomous" as opposed to 'autonomous' approach to understanding architecture, giving agency to client, the public, the media, the politician and the building professions in the development of architectural product' (McNeill 2009:3). This perspective demonstrates the fact that architectural practices and architects are driven by multi-layered powerful agents and actors. Therefore, it could be difficult for 
architects to retain their autonomous freedom to build their masterpieces in their own right. They have to negotiate and adopt to the corporate processes of transnational political and financial power in the era of the global capitalism.

Hence, iconic architecture cannot be understood just as a nation-led-political device or signature of architects, but also a site for the investment, promotion and justification of the social status of 'transnational urban elites'. There has been some discussion of the significant features of transnational global elites in terms of their changing relationship to iconic architecture and cities. To indicate this new trend, Kaika (2011) emphasises that after the 1970s, the relation between global cities and corporate patronage, dramatically changed.

\footnotetext{
'Along with the eclipse of the 'traditional' economic (and cultural) activities in Western cities, the 'traditional' species of the place-loyal urban tycoon (such as Guggenheim, Rockefeller and Ford etc.) that would tie his personal fortune with that of the city, was also eclipsed' (Kaika 2011: 975 () added). ${ }^{1}$
}

'The traditional species of the place-loyal urban tycoon' who involve in the production of urban space and the reproduction of urban life, have been superseded by rootless transnational elites. They 'tend not to associate themselves with any specific city or locale and have no particular interest in urban social and political life' (Kaika 2011:975). They are also not interested in 'traditional' concepts of corporate iconic architecture which often have a public space where workers and city people can share. Whereas the iconic buildings of transnational corporation can be seen as 'self-contained machines' (Tafuri, 1980 cited in Kaika 2011:977). It is often 'gated' buildings which act 
predominantly as branding objects of transnational corporation' (Kaika 2011:977) to act just like huge three-dimensional advertisements.

These buildings are built for, what Sklair calls, the 'Transnational Capitalist Class'. They are often people who work in banking and media institutions, business consultants and lawyers. Sklair explains that 'in pre-global era (roughly the period before the 1960s) iconic architecture tend to be driven by the state and/or religion, while in the era of capitalist globalization, the dominant force driving iconic architecture is the transnational capitalist class' (Sklair 2010:138). Hence, given the current situation in the political economy of architecture, contemporary architects have to engage in self-promotion to become more favourable to global financial power.

\section{Branding and commodified iconic architects}

Yet before the advent of the 'transnational capitalist class', there have been many celebrities in modern architecture history, Le Corbusier, Ludwig Mies van der Rohe and Frank Lloyd Wright to name but a few. McNeill states '[t]he conditions for the emergence of a star architect have long been in place, but the nature of architectural 'stardom' is a complex issue' (McNeill 2009:64) and Horne also indicates 'the changing celebrity status of architects and architecture during the $20^{\text {th }}$ century' (Horne 2011:208) and the increasing growth of 'the values of currency of the "famous" dominate architectural culture'(Till 2009:42 cited in Horne 2011:208), and 'the production and marketing of architectural iconic buildings and signature architecture' (Larson, 1994: 470 cited in Horne 2011:208) since the 1980s. In his discussion on the production of architectural iconicity and its relationship to contemporary global capitalism, Sklair explains 'how the dominant forms of contemporary iconic architecture arise and how they serve the interests of globalizing capitalists' 
(Sklair 2006:21). He argued that 'transnational capitalist class' have increasingly become a central power to 'define the times, places and audiences that make buildings, space and architecture iconic' (Sklaire 2006:21;2010:138, emphasis added).

If we follow the ideas of 'the values of currency of the "famous" dominate architectural culture', and 'the production and marketing of architectural iconic buildings and signature architecture' come to be a central factor in contemporary architectural production, it is then important for some successful architects who are famous and running international leading architectural companies with rich resources, ${ }^{2}$ to not only become powerful star architects, but to make themselves into powerful 'brands'.

Architect and cultural theorist, Daniel Libeskind argues that this provides an interesting social recognition of 'Starchitects': First, 'they are identifiable individual, with a name, a face and perhaps some kind of authored book', second, '(their buildings) are often associated with striking shapes, surfaces, or concepts' and third, 'many of these individuals have a strong capacity for selfpromotion' (see McNeill 2009:62). To further the analytical understanding of 'self-promotion', McNeill further discusses '(The Hollywood) star system' which became the major apparatus to create charismatic stars for the screens. He remarked on the similarities with the production of architectural celebrity in terms of its 'systematic, industrialized process of promoting individuals with a particular uniqueness or distinctiveness,' (McNeill 2009:64).

This suggests that iconic architects are socially constructed products. They strategically commodified themselves to become 'iconic brands'. In 1990s Frank Gehry and, his masterpiece, Guggenheim Museum in Bilbao and its 'Bilbao 
effect' (a single piece of architecture transformed a de-industrializing Basque city into a world famous pilgrimage and tourist site to stimulate the local economy) can be seen as the classic example. ${ }^{3}$

\section{Architects, designer and commerce}

A Pulitzer Prize winning architecture critic Paul Goldberger described 'Mr. Gehry is an architect of immense gifts who dances on the line separating architecture from art but who manages never to let himself fall.' This is a good testimony of Gehry's long standing relationship with the arts. ${ }^{4}$ Yet, a close affiliation between architecture and the arts is not new with one of the most salient early phases dating back to the early 1900s - Bauhaus. Founded by Walter Gropius in 1919, Bauhaus was a school which was intended to 'institute as artistic consultancy for industry, commerce, and the crafts' and for the 'co-operation between the artist, the businessman, and the technician' (Issacs 1985:152-153 cited in Volkmann \& De Cock:2007:390). Although the dream of Gropius had faced serious problems several times with both inside and outside conflicts (business management and political circumstances), and finally closed down in 1933, we can still find today much evidence of his prescient philosophy in contemporary architectural and art practices.

Gehry established a partnership with Tiffany \& Co. in 2003 in order to start a luxury jewellery collection which launched in 2006. The attractiveness of their products is '[L]ike his buildings, Mr. Gehry's jewelry and home collection exude vitality, with Tiffany skillfully realizing the spontaneous twists and turns of the architect's inventive style' (Frank Gehry in About Tiffany \& Co.). ${ }^{5}$

The collaboration of star architects with high-end fashion brand is not uncommon. Rem Koolhaas, Jacques Herzog and Pierre de Meuron along with 
other designers have contributed to Prada's Autumn Winter 2018 menswear collection. Koolhaas created a compartment designed backpack which, he mentioned, to be worn on the front of the body for 'the contemporary urban citizen' who are transnational high-mobility people. They are people who can be major clients of his architecture projects. Koolhass's research lab AMO also contributed to create the set for the show (Morby 2018).

One of the world renown female architect, Zaha Hadid was also involved with the fashion industry working with famous brands such as Louis Vuitton, Fendi, Adidas, United Nude etc. As known as 'the Queen of the Curve for her architectural innovation' (Black 2016), most of her designed fashion items evidently have her artistic 'signature' which often challenged conventional concepts of established brand items and attempted to reinterpret forms and material. There were recognisable as her own art work.

The collaboration with Brazilian shoe brand Melissa gave her the chance to use digital modeming technologies. Using plastic as basic material, the form of her designed shoe successfully materialized a perfectly balanced streamline.

[Figure 1 Zaha Hadid x Melissa @ Melissa]

Her beautiful curve also appeared in the collaboration with Louis Vuitton. Her designed bag was produced in moulded plastic which shapes beautiful layered curves with different colours, featuring an image of a moment of never-ending movement.

[Figure 2 Zaha Hadid x Louis Vuitton (c) Louis Vuitton] 
Her contribution created not only a unique shape and style, but also a conceptual challenge which expanded the categories of the 'iconic LV Bucket Bag' from practical usage as a container to a piece of art display.

\section{Zaha Hadid as a multifaceted identity}

Hadid was categorized " $A$ " list of name brand architects. She was the first female winner of the Pritzker Architecture Prize (2004) and she was also awarded the RIBA Stirling Prize for two consecutive years $(2010,2011)$. Born in Baghdad, Iraq in 1950, she established her career as an architect in London since 1972 and has been acknowledged by 'World's Most Powerful Women' in the Forbes and TIME magazines who included her in the '100 Most Influential People in the World.' The Japan Art Association also presented her with the "Praemium Imperiale' (Zaha Hadid Architects). ${ }^{6}$

She remarked that her own architecture provides a 'new image of architectural presence' with 'dynamic qualities such as speed, intensity, power, and direction' (Foster 2013:83). Her architect has often been described as 'the utopian visions of Suprematism and Constructivisn into the promised land of actual building' (Foster 2013:85). Like Frank Gehry's works, her architecture stands for striking contemporary urban spectaculars.

As her projects caught public imagination across the globe, her own presence become more noticeable to the public. This could partly be seen as a result of receiving the prestigious awards and prizes for her contribution to 21 th architecture that helped generate more opportunities to appear in the media. This could be also as a result of the way that prominent of art museums have started to make connections between art and architecture. This conjunction was, indeed, not a new trend. Over the last fifty years, many artists' design, 
paints and sculptures have been incorporated into part of the architecture, and many architects has started to intervene in visual art during the same period (Foster 2013: vii). However, the collaboration today become a 'central activity' for branding the city in contemporary cultural economic practice.

Foster writes,

(Artists and architects) [s]ometimes a collaboration, sometimes a competition, this encounter is now a primary site of image-making and space-shaping in our cultural economy. Only in part is the importance of this conjunction due to the increased prominence of art museums; it involves the identity of many other institutions, as corporations and governments turn to the art-architecture connection in order to attract business and to brand cities with art centers, festivals and the like (Foster 2013:vii, emphasis added).

As part of this trend, like other starchitects, Hadid's architectural projects have been exhibited by many leading art museums, featuring as a contemporary art form. The company Zaha Hadid Architects's projects appeared New York's Solomon R. Guggenheim Museum in 2006, London's Design Museum in 2007 Saint Petersburg's State Hermitage Museum in 2015 and London's Serpentine Galleries in 2016 (Zaha Hadid Architects). ${ }^{7}$

Hence, her public recognition and identity become multifaceted: architect, designer, and artist. She was involved not just in architecture, but extended to the field of art and design which is a significant part of cultural production, as her company, Zaha Hadid Architects announced '[w]e are in the business of 
cultural production' in 'about us movies' of the official site of Zaha Hadid Architects. ${ }^{8}$

\section{Zaha Hadid and global brand}

Being recognised as an avant-garde contemporary architect, she developed her hybrid talents to contribute to 'co-operation between the artist, the businessman, and the technician' (Issacs 1985:152-153 cited in Volkmann \& De Cock:2007:390) in the contemporary cultural industries. In other words, she has contributed to the collaboration between architecture, art and commerce in contemporary cultural industries. This is partly because her philosophy was based on a challenge to conventional concepts and ideas of architecture to provide new 'design at all scales' from city planning, architecture, interior, artefact, even fashion in order to propose new ways of life (Zaha Hadid Architects). ${ }^{9}$ But this could also be seen as an important marketing strategy of self-promotion to become a new global brand.

The brand provide not just various types of products and design, more importantly creates a set of meanings, new value and narratives to integrate into images of a product, a company or a person. Brading can be perceived as a significant system for cultural production. In this discussion of cultural production, drawing on Walter Benjamin's pessimistic idea of losing 'the aura' of the work of art in age of mechanical reproduction, Urry and Lash critically argue, 'if we begin not from the metaphor of the cultural economy, but from the real economy, -- what is called production is in fact design, product development or R\&D' (Urry \& Lash 1994:123). They continue,

Here is it argued that culture, which once in a golden past was part of a 'sacred', is becoming more and more like manufacturing industry. 
Our point is rather the opposite. Even in the heyday of Fordism, the culture industries were irretrievably more innovation intensive, more design intensive than other industries. --- our claim is that ordinary manufacturing industry is becoming more and more like the production of culture (Urry \& Lash 1994:123, emphasis added).

What the production of culture actually does is 'creating the value-added which is not cognitive knowledge but a hermeneutic sensibility' (Urry \& Lash 1994:123). In other words, 'the cultural industries become more like business service and produce increasingly not like commodities, but advertising' (Urry \& Lash:142 emphasis in original).

Hence, as the manifesto of Zaha Hadid Architects (' $[w]$ e are in the business of cultural production') shows, it is significant for contemporary architects to create not just the material, but also provide the immaterial values, that is 'images' with 'a hermeneutic sensibility' (Urry \& Lash 1994;123) - creating a set of new ideas, meanings and sensibilities in the cultural industries. Most of consumer goods, products started to become something exclusive, fascinating, exciting and appealing, all of which evokes a sense of aesthetic. This is a formation process of the brand. This process can also be applied to Hadid herself so as to become a successful brand. She had to promote herself as a producer as well as 'as a product within a brand-name structure of cultural marketing' (Frow 2002, 63).

In order to make themselves into global brands it is significant for architects to obtain commissions for mega-projects, which are often associated with flagship buildings for global companies (e.g. The Shard in London), landmark facilities for global events (e.g. Olympic stadia), cultural/educational spaces for the 
public (e.g. museums, theatres or libraries) or consumption/entertain public spaces (e.g. complex large-scale malls). All these projects embrace 'iconic' architecture which strictly require a sufficiently persuasive, inspirational, and highly distinctively aestheticized visuality, which is unmistakably identified as a signature of a particular star architect in symbolic economy.

Frow states,

\begin{abstract}
Both the aesthetics of the signature and the aesthetics of the brand are ideologies: they are regimes of marketing and authorization which draw in rather similar ways on an imaginary of the unique person or of personality: brands have a "personality" because they make use of strategies of personalization (the use of characters, celebrities, direct address) to create something like a signature-effect; signature stand as metonyms of an originating author or artist (2002: 71-71).
\end{abstract}

In this sense, iconic architecture and its architects have become overlapped and incorporated into an 'ideologically' constructed global brand and these have become inter-changeable semiotics. In this rendering, iconic architecture and its architect are acknowledged as an identical brand. Hence, one can feel that Hadid's signature building can be seen as very existential metonyms of herself.

\title{
Zaha Hadid and Tokyo Olympic Stadium
}

In order to generate an 'ideologically' constructed global brand, it could be most beneficial to acquire a complex and ambitious grand project, such as an Olympic stadium, since it is one of few occasions in which architecture becomes a matter of public interest and debate. In this light, the issue of design of the Olympic stadium often draws a good deal of media attention which offers an influential opportunity for self-promotion and self-branding. 
Zaha Hadid won the 2020 Tokyo Olympic Stadium competition.

The competition committee consisted of specialists from architecture (including two British architects, Richard Rogers and Norman Foster), sports and culture events and the Japan Sport Council. The chairman, celebrated Japanese architect, Tadao Ando, commented, '[The winning scheme's] dynamic and futuristic design embodies the messages Japan would like to convey to the rest of the world'. ${ }^{10}$ Ando's comment implied that, he believed, Hadid's plan could represent a positive image of Japan. This process can be understood as part of a strategy of the nation branding. This sentiment might be based on the implicit premise - The 'global' brand, Hadid can produce a 'global' standard quality stadium which could convey a 'global' high standard image of Japan.

One of the most appealing aspects of the design to the jury was the retractable roof which creates 'exaltation, presence (ambience), and integration' and the realization of the roof construction will show the high level of Japanese architecture technology to the world. ${ }^{11}$

But the process of the competition was scrutinized by a well-established leading Japanese architect, Fumihiko Maki. He points out the lack of clarity in the requirements; no detailed explanation of ratio of the floor plan against the total floor scale (about 225,000 square meters); insufficient mention of necessary documents (e.g. the need for a 3D architecture model); architects who were allowed to submit to the competition should be from well-established and award-winning groups only (such as Pritzker prize-holders); there is little clear logistical relationship between design supervision and construction management (Maki 2014, pp 40 onward). Furthermore, according to an architect, Nagashima, there was a more serious problem: the lack of local 
communities' participation in the competition's decision-making process. He argues that fairness in architectural and city planning relies on uniform regulation which is indicated and measured by 'quantities', such as the proportion of building volume to lot and floor area ratio, but this system could interfere in the understanding of lived community environments, including local history, landscape, and economic activities. In the case of the Jingu-Gaien area where the new national stadium was planned to be built, there was a high cultural valued and historical significance along with a precious mature nature and ecosystem. All these issues were pushed to the back of the list or excluded from the new national stadium plan (see Nagashima 2014, 173).

Hadid's plan itself has also faced widespread criticism and intensive debate. She designed the 80,000-seat and 70-metre-high Japan National Stadium. The budget (252bn yen/£1.3bn, $\$ 2 \mathrm{bn}$ ) was double the original plan. The stated official requirement for the project total floor space, as mentioned earlier, was about 225,000 square meters. This was much larger than the London, Sydney and Athens stadia (see Maki 2014, 47), but Hadid's plan still went oversize (291,000 square meter. In addition, this was 8 times bigger than the Yoyogi National Stadium built in 1964). Therefore, there was the major risk that the existing site-specific historical meanings of the memories of the Meiji Emperor in this area could be damaged. The oversize plan also created anger from the 300 households notified that they were to be evicted from the nearby Kasumigaoka apartments.

After viewing the revised stadium design, the budget was scaled down - $40 \%$ reduction in budget [from $300 \mathrm{bn}$ yen ( $1.8 \mathrm{bn}$ pound) to $169 \mathrm{bn}$ yen ( $970 \mathrm{~m}$ pounds)]. Yet, it still could not gain a satisfactory reaction from Japanese architects and the public. One of the internationally well-known Japanese 
architects, Arata Isozaki states 'if the stadium gets built the way it is, Tokyo will surely be burdened with a gigantic white elephant' (McCurry 2015). Fumihiko Maki also published his article on the design of the new national stadium and protested against the plan in JIA Magazine in 2013. This led to organizing symposia and workshops which discussed the new national stadium; a symposium, 'reconsidering the design of new national stadium in the sitespecific historical context' with Fumihiko Maki et. al. in November 2013; a public workshop 'let's learn about how the national stadium should be' with Mayumi Mori ${ }^{12}$ et. al. in January 2014; a symposium, 'another possibility for the new national stadium' with Toyo Ito et. al. in May 2014; the international symposium 'Aesthetics for the city and architecture: case of the new national stadium' with Fumihiko Maki et. al. in July 2014.

These activities are, however, not uncommon. McNeill writes,

[F]or many critics, iconic buildings are unhealthy, not least because they attempt to upstage each other, are often disrespectful to urban context, can be accessibly expensive, and - the greatest crime of all? - can reduce architecture to mere surface decoration, and the architect to confectioner (2009:95).

These criticisms of Hadid's mega-structured Olympic stadium was not an exception.

\section{Public voices in the blogsphere}

The criticism towards Zaha Hadid's design for the Tokyo Olympic stadium was found in various public events and print media, but also in Internet dialogues. Here, we need to bear in mind that media representations of architectural plans 
and political influence from Internet citizens have been considered as a significant process for establishing the legitimacy of the projects with the public. ${ }^{13}$

Daniel Dayan, applied the notion of 'hijacking' to the event, arguing that ' $[t]$ he Olympics are constantly being, or threatening to become, "hijacked" by a wider range of agents: local and global markets, governments, celebrities, political activists, terrorists' (Dayan 2008: 399 cited in Kang and Traganou 2011:152153). Related to this observation, Miah et al (2008) critically points out the emergence of new type of journalism. It has been called a "reprofessionalization"14 of journalism which occurred with the rise of the 'citizen journalists'.

'Citizen journalists' refer to 'the expansion of journalistic expertise that is achieved by the multiplicity of publishing channels which became available with the rise of new media' (Miah et al. 2008: 455, 486 cited in Kang and Traganou $2011: 153)$. It is argued that since the advent of the Web and its communities are expanding as a shared platform of cultural specialists or cultural intermediaries (Bourdieu 1986;Featherstone, 2007)and ordinary people, the hierarchal ordering of influential power in cultural production has shifted. This suggests that voices, which used to be unable to participate in social and political discussions, are now able to take part in various online dialogues. Given such conditions, public concern, such as the Olympic national stadium becomes one of the central topics in the wider discussion of Olympic events. The discussions and dialogues are created by those who are concerned with the political conflicts of ideologies, interests from various competing groups. Such public platforms make up the so-called 'blogsphere' (Kang and Traganou 
2011:155), which became a public sphere for exchanging and discussing architectural dialogue amongst citizens.

The criticisms of Zaha Hadid's design for the Tokyo Olympic stadium in the Internet dialogues can be seen as a good example. It is not uncommon that architectural projects are often cancelled by citizens' protest. The net-users who are not only architectural critic or professionals, but also those who seem to be like-minded people who are not necessarily architectural critics or specialists (architects), started to criticize and shows negative opinions about Hadid's design though internet social media.

An architectural critic, Takashi Moriyama started in his blog 'about the debates of the new national stadium competition' in November $2013^{15}$; the custodians of the national stadium, Tokyo has started their blog in October, 201316; a writer, broadcaster and neuroscientist, Kenichiro Mogi tweated to support Maki's proposal in June $2015^{17}$. There were also articles posted by not-wellknown or unknown bloggers: such as 'Is the new national stadium Hadid's curse? Comparison of its cost with that of the other Olympics'"18; 'Zaha Hadid "is it really true that the new national stadium will be constructed?"'19.

Consequently, their negative narratives against Hadid's design and other related political issues around the Olympic stadium project, increasingly gained a good deal of public attention. The collective and shared critical views toward Hadid's architectural plan gave strong influential impetus to the government decision process and as is well known it was cancelled in the end. This is a social phenomenon that develops in the information society. What Cass Sunstein calls 'cybercascades' which means that ' $[\mathrm{w}]$ ith respect to the internet and new communications technologies, the implication is that groups of likeminded people, engaged in discussion with one another, will end up thinking 
the same thing that they thought before - but in more extreme form' (Sunstein $2001)^{20}$.

Even after the governmental formal cancellation had has been made, on $25^{\text {th }}$ August 2015, Hadid's office announced their design's promotion video which obviously deliberately sought to appeal to Japanese citizens to legitimate the appropriateness of their design. But it was too late to subvert negative public opinion and to establish proper legitimacy between Zaha Hadid Architects, the government, and citizens. We should take into account the way in which the Olympic stadium is a space, which is produced by wider social-political contexts (e.g. star-architects, bureaucracy, and capitalism), but also a space mediated by public spaces, which can be re-constructed and influenced by the unprecedented degree of audience participation though broader dialogues between internet users (see Kang and Traganou 2011).

\section{The nature of brand}

Yet the failure of Hadid's project cannot be understand without further considering the nature of brand. Frow emphasizes two aspects of brand identity. The first element is that brands have 'personalities', that is, 'brands have personalities in their own right, whereas commodities do not' (Haigh 1998:8 cited in Frow 2002;68). This means that commodities or products advertised with invented images and narratives help to create their personalities. The personalization of brand can be found evidence in a way which many celebrities, 'brand characters', endorsed products. Their personal imaginary significance transfer to commodities in order create 'a semiotic surplus value' (Frow 2002:66). Yet this can also create 'a semiotic negative value', if brand character carries unpleasant or unacceptable images and narratives toward the public (consumers, audiences and citizens). 
The second is that 'brands and brand advertising seek, by means of the specular circularity of applied market research, to invoke a recognition-effect in consumers. This means that brand reveals symbolic value 'as a reflection of the buyer's self-image' (Kapfere 1992:2 cited in Frow 2002:68). As such branded commodities can 'provoke a mirroring identification with the brand on the part of the consumers of the brand image'. This is a process of imaginary identification which is based on 'the source of the brand's non-rational hold over the buying behavior of the consumer' (Laplanche and Pontalis's 1973:210 cited in Frow 2002:68).

If we follow this logic, Hadid's super futuristic avant-garde Tokyo Olympic stadium might reflect on an image of Japan itself. This is because unlike pursuing world-recognized symbolic buildings for headquarter of transnational companies, the Olympic stadium can be seen as a national symbol. The stadium is commission by public bodies. It is intentionally designed to be an architectural icon in order that the stadium can function as a showcase of Japan toward the world (nation branding) as well as help to create a positive selfimage for Japanese citizens (self-esteem). The stadium can therefore mirror national self-identification.

In this rendering, it could be useful to explore representations of the stadium in the internet in order to illuminate the associations between images of the stadium and national self-identification. There are many articles on the ways which the stadium could be likened to everyday 'objects': 'Could it become the Olympic stadium? Cyclist helmet shape of the new national stadium' in 2012 November (AFP, BB News 2012)21; 'Go-kart, helmet, potty? Alternative uses for Zaha Hadid's Olympic stadium' in July 2015 (anon in Guardian 2015) ${ }^{22}$. All these negative complains can be understood as revealing the general unease with identifying the stadium as a national symbol in the public domain. 
[Figure 3 Zaha Hadid's revised design of the Tokyo Olympic Stadium]

This suggests that the Hadid designed stadium was seen as an architecture evoking 'semiotic negative value' against existing landscape, memories, meanings in the site, the Jingu-gaien region in Tokyo. As a result, there was a huge gap between Hadid's Olympic stadium's symbolic image and Japan's national self-identity.

Interestingly, the words, 'shame and embarrassment' can be also often used to evaluate the stadium design in media texts: Fumihiko Maki remarked that '(the new stadium) will be sneered at and will be an embarrassing construction. ${ }^{23}$ : emeritus professor of Tokyo Institute of Technology, Sachihiko Harashina stated, '[the plan of the new national stadium] is embarrassing'24; a critic and anthropologist, Shinichi Nakazawa also mentioned ' (I) feel embarrassed with the new plan which ignored the history of Jingu region'. ${ }^{25}$ The Hadid's design image has been described using 'disgraceful' metaphors (helmet, go-cart, potty) and regarded as 'something shameful or embarrassing'.

It is argued that what is common to 'shame and embarrassment' ${ }^{26}$ is that both are forms of self-awareness that reveal the painful states in which 'the individual believes she or he has failed to meet appropriate standards or conduct, and is seen to have done so in the eyes of others' (Crozier 2014:273). At this point, we can see psychological reflections in the usage of the words. This suggests that Japanese people felt 'shame', because Hadid's design failed to meet the appropriate standard. People are also 'embarrassed', because such failure could be seen by foreign countries. Such psychological reflections can be understood as threatening the Japanese people's self-esteem. Hence the Hadid's new national stadium can be seen as a painful and unacceptable image of Japan. This suggests that the power of global architectural brands doesn't always succeed in changing conventional values and work to create new lifestyles through transformed urban landscapes. In other words, the Hadid's aesthetic icon which was explicitly designed for a distinctive moment in a city 
project, part of the 2020 Tokyo Olympics, in order to create a new socially, culturally and politically meaningful form, failed.

\section{Banalization of global iconic architecture}

The attempt at the mobilization of a new aesthetics can also cause a weakening in the power of brand. As discussed, branded architecture's political relationship to the global economy entails creating a semantic matrix, which construct architectural meanings and aesthetics. In other words, these contemporary cultural forms necessarily have to be embedded in global capitalism. Kaika remarks that

[T] he public role and life expectancy of today's 'iconic' commissions, alongside pressure for quick turnover, inevitably have an impact on the building' design and production process. Whilst the dream of every self-respecting early-20th century architect was the freedom comprehensively to design every detail of his or her building, the pressure of quick turnover lead today's star architects to adopt a more corporate approach to the creative process (Kaika 2011:979 emphasis in original).

For Kaika, contemporary architects have lost their ability to pursue totalizing design ideas and ideals and started 'the repetition of successful architectural design forms across the world' (Kaika 2011: 980). Hence, she argues that '[d]spite the 'star status of these architects, their uncanny replicas of successful earlier models can hardly be descried as 'original' (Kaika 2011: 980). The point Kaika made is that star architects repeatedly produce their successful design forms and apply 'the same design code to express a multiplicity of meanings in different social and geographical contexts' (Kaika 2011: in the figure caption 980). 
Hence, there are always contradictions between the global brand's transnational form and value, and the site-specific history, memory and meanings. Horne remarks that the paradox of distinctiveness lead to 'unspectacular spectacles' (Horne 2011: 281) and the gap between the various narratives, imaginaries and themes of 'the spectacular global' and 'vernacular local' (Horne 2011: 281). These conditions create 'spectacular local resistance to and/or negotiation with the global spectacle through novel uses and vernacular appropriation of the built environment' (Horne 2011: 281). This also suggests that the sport stadium as a space for generating collective memories can be also seen as 'a forum for cultures of commemoration' (Russull, 2006 cited in Horn 2011:281). More closer to this point, unlike eye-catching novel designed corporate buildings for global companies (what Kaika calls 'autistic architecture' which are only for people in the company and do not engage with urban political life), the sport stadium should be a public space which have to be acceptable and open to everyone.

To turn to Hadid's Tokyo Olympic stadium, we can consider how her 'signature architecture' could encapsulate various problematic issues. As a global brand, her Tokyo Stadium designed noticeably applied her signature form in using sweeping curvy streamlines and a computer graphic rendered dynamic shape. A similar form and design code can be easily found in her many other architectural projects, such as, London Aquatic Centre and Al Wakrah Stadium (Scheduled inauguration in 2018). This practice leads to the loss of features of distinctiveness, and the designs can therefore become 'unspectacular spectacles.' An oft found criticism of iconic buildings in general and Hadid's Olympic stadium in particular, is that it can be seen as a product of the architect's over-self-consciousness and a lack of concern for the local context. This could cause to generate 'a semiotic negative value' for local communities. 
The stadium should have incorporated sight specific narratives, memories and themes into the symbolic aesthetics of its architecture design.

[Figure 4 London Aquatic Centre designed by Zaha Hadid Architects]

[Figure 5 Al Wakrah Stadium designed by Zaha Hadid Architects]

Moreover, as mentioned earlier, Hadid's brand signature can be found in not just architecture, but also vernacular everyday objects, include furniture, handbags, shoes, fashion accessories, flower vases, and chandeliers. The more her signature can be found, the more Hadid's brand exclusiveness and scarcity value become weakened.

The deployment of brand signature for goods implies that value of the brand, which used to be for only exclusive objects, has now become a component of large-scale mass cultural production. The proliferation of brand signature can lead to declining power of the brand. Yet it can be the immanent nature of brands, since process of the 'iterability and seriality' (Frow 2002:71) of appearance of the brands only enable a particular products or producer to make it/he/she possible to become 'a brand'.

In this sense, the broadly distributed Hadid's signature and image of branded products ('objects' as well as 'herself') were always already implied in the very nature of the brand - its powerful, but inherent contingency and ephemerality. Hence, the Tokyo Olympic stadium as one of the most powerful of Hadid's signature products can be identified as the very existential archetypal case of iconic architecture, since it was a 'branded' stadium (therefore, 'exclusive'), but it has to be accessible to everyone (therefore, 'vernacular'). The stadium was promoted to blur the boundary between the value of the 'brand' and that of mass-production. Therefore, Hadid's global brand was not able to sustain its symbolic matrix of brand power in the context of the construction of the 2020 Tokyo Olympic stadium. The Olympic stadium should be expected to become a 
legacy which is a lasting stable singular entity as a symbol of the 'eternal' established nation.

\section{Conclusion}

Hadid's Tokyo Olympic stadium plan and its trajectory provides a good example to understand the shifting role and identity of iconic architects and 'branded' architecture in the era of global capitalism. Focusing on the Olympic sport stadium as a contested juxtaposition of political power, economic interests and symbolic capital, the paper attempts to analyse branding as a concept, which helps to understand the reciprocated hermeneutic relationship between the material (architects and architecture) and the immaterial (a set of new symbolic value and narratives). Branding is a powerful system to reinforce the symbolic matrix of not only commercial goods, architecture and architects, but also the image of the nation. This is because branding is not just an economic practice, but a cultural production, which involves the creation of powerful imaginaries. Such imaginaries inspire the creation of new narratives, ideas and sets of symbolic values. If we follow this logic, we can understand that a star architect (in this case, Zaha Hadid) who was an established global brand could act as a significant narrative-maker for the new image of Japan, by providing her innovative architecture designs which have been globally well-received. However, the creation of new narratives, ideas and sets of symbolic values for the Olympic stadium was put forward by various stakeholders with different interests, needs and hopes: global financial powers, nations, media, citizens and branded architects. Hence, creating processes of dominant narratives (the immaterial) have been intensively contested in neoliberal capitalism which is a competition-based and profit-oriented system.

Branding architecture and creating star architects are a newly found pragmatics for surviving in the competitive architectural industry. Narrativization and commodification of star architects and iconic buildings are necessary to promote their higher public profile and making 'themselves' into a global brand. 
She was a star architect and the most manufactured icon. Hadid, however, ultimately failed to provide a new collective imaginary, which would invent new values, meanings, narratives and novel sense of aesthetics by proposing her mega scale of architecture design. Her failure suggests that the power of brand could be subject to various contested environmental contingency.

Defusing the power of brand can also be discussed in terms of its immanent nature. Brands reveal symbolic value 'as a reflection of the buyer's self-image'. In this logic, there was a discrepancy between the symbolic value of Hadid's architecture and the imaginaries of Japanese self-identity. Also, the repetitive design as artistic signature of iconic building can always generate contradictions: 'unspectacular spectacles' (Horn 2011:218). Furthermore, the wide diffusion of her signature in consumer goods leads to the weakening of the distinctiveness and exclusiveness of her brand image. ${ }^{27}$

Needless to say, the idea of branding is often used in business merchandise and marketing. As discussed earlier, the idea of nation branding has been basically developed by applying business model of merchandising. Hence, we can see that the 'branding nation' can be seen as a form of 'merchandising nation.' In this sense, a nation is not a commodity, but it become a commercialized entity. The same logic of commercial merchandising applies to nation branding in 'selling' a preferable image with high symbolic value. What is difference is that the benefits of nation branding are not (direct) monetary profits, but the acquisition of prestigious higher national ranking in order to gain political and economic power. Another difference is that a nation can be seen as an 'imagined communities' (Anderson 1991) and it is, unlike a commodity, an intangible entity. Hence how to represent a nation becomes increasingly significant matter. It can be said that representing 'national culture' as 'soft power' (Nye, 2005) is often considered as a powerful strategy. 
National culture in the era of global branding has two distinctive features which have to be incorporated. One is the culture which has global standard quality with new value and is often invented and novel. The other is the culture which has local standard quality with conventional value and is often stable and traditional. It is always challenging to integrate 'alien' global culture into the indigenous local culture, since there is always a need for a destruction and reconstruction process within the existing value and system. Hence, it can be considered that 'creating a national culture' requires careful re-invention of narratives, memories and meanings. This process can also overlap with the legacy creation process. Legacy is a not fixed existing entity, but always inventing and re-inventing to integrate with new narratives, memories, meanings, in order to accord with socially dominant power. In this sense, we can see that Hadid's plan (even though it was regarded as a global standard quality), failed to become socially influential. This is why Hadid's aesthetics and narratives for the Olympic stadium could not adequately re-invent narratives, memories and meanings of the image of Japan so as to become a 'new' national cultural legacy.

After Hadid's design was cancelled, a Japanese architect Kengo Kuma took over the Tokyo Olympic stadium project. ${ }^{28}$ He does not seek to create spectacular buildings, but to 'naturally merges with its cultural and environmental surroundings, proposing gentle, human scaled buildings --- constantly in search of new materials to replace concrete and steel, and seeks a new approach for architecture in a post-industrial society' (Kengo Kuma and associates). ${ }^{29}$ Wood is his preferred material. Concrete and steel can be seen as a symbol of $20^{\text {th }}$ century modernity, but he uses natural wood instead. For him, wood could be the best material to reunite people and nature by creating nearly-forgottennatural aesthetic sensitivities. Kuma's challenge as an architect in 21th century contemporary society seems to subvert the logic of modernity which is seeking alternative idea of the mass production and banality of 'distinctiveness'. 
The Tokyo Olympic stadium should be a singular and original entity. However, it can be very hard to avoid being driven by the contested rationalities between local politics and global capitalism. In the hope, Kuma's architecture language for the 2020 Tokyo Olympic stadium should be accepted by site-specific environments, and inspire positive imaginary of national self-identification, all of which could create narratives of the stadium as legacy for the next generation. But this hope still leaves a question.

\section{Notes}

1 Kaika observes that iconic corporation buildings, such as the Rockefeller Centre, were designed not only for the glory of private capital, for providing luxurious environment for employees, but also for educating civil society to new aesthetic sensibilities through cultural practices. All these claims and activities inspired a sense of belongings to the city and even a sense of national pride (see Kaika 2011:974).

2 See more detail in John Horne (2011: 211 onward).

${ }^{3}$ An architecture critic Hal Foster, speaking about Frank Gehry in Sydney Pollack's film Sketches of Frank Gehry, "he's given his clients too much of what they want, a sublime space that overwhelms the viewer, a spectacular image that can circulate through the media and around the world as brand" (Moore, 2017).

4 'Gehry's relationship with the internationally heralded printmaking studio, Gemini G.E.L. (Graphic Editions Limited), dates back to the 60's, two decades after Gehry first moved to sunny Los Angeles from Toronto'. (Kennedy 2017). 5 http://press.tiffany.com/ViewBackgrounder.aspx?backgrounderId=2 (Accessed 31 March).

${ }^{6}$ http://www.zaha-hadid.com/people/zaha-hadid/ (accessed 3 April 2018).

7 http://www.zaha-hadid.com/people/zaha-hadid/ (accessed 3 April 2018).

8 Video clip 'about us movies' in the official site of Zaha Hadid Architects http://www.zaha-hadid.com/videos/ (accessed 4 April 2018).

9 Video clip 'about us movies' in http://www.zaha-hadid.com/videos/\#about-us (accessed 4 April 2018).

10 https://www.architectsjournal.co.uk/home/zaha-hadid-wins-japan-nationalstadium-contest/8638748.article (accessed 13 Jan 2019)

${ }^{11}$ https://www.jpnsport.go.jp/newstadium/Portals/0/NNSJ/winners.html (accessed 13 Jan 2019)

12 The writer Mayumi Mori as a citizen, and the representative of 'the Custodians of the National Stadium, Tokyo', actively promoted critical views of the 2020 Olympic stadium.

13 There is an interesting episode of Kenzo Tange's 'Plan for Tokyo 1960' project, regarding media representation and public legitimation.

The project was designed for the rapidly increasing industrial and urban sprawl, to provide a new urban proposal for the city's future. When he announced though Japan's national television network NHK in a special TV programme, his ideas were not published in an architectural journal, but the popular news journal Shukan Asahi (Asahi Weekly). As the result of this, the plan got 
instant attention from the public. (Lin 2009:144-146). The plan was eventually read by governmental officials as a potential national project. Although the plan was never realized; at this point his plan was acknowledged and to some extend accepted by the public. But it must be noted that this success was made in the pre-internet society (see Tamari 2014).

${ }^{14}$ Miah et al note that 'we do not claim that journalism is de-professionalised via new media, as this would neglect the advanced skills, ethics and integrity of so-called citizen journalists. Instead, our re-professionalisation refers to the expansion of journalistic expertise that is achieved by the democratization of technology and publishing channels' (Miah et al 2008, Note 2: 486).

15 https://ameblo.jp/mori-arch-econo/entry-11646600598.html (accessed 28 June 2018).

${ }^{16}$ 2020-tokyo.sakura.ne.jp (accessed 28 June 2018).

17 https://twitter.com/kenichiromogi/status/615657064275161088 (accessed

28 June 2018).

18 https://www.huffingtonpost.jp/2014/06/23/how-much-new-national-

stadium_n_5520920.html (accessed 28 June 2018).

19 http://burusoku-vip.com/archives/1757469.html (accessed 28 June 2018).

20 C. Sunstein' s 'echo chamber' (2007) and E. Pariser's 'filter bubble' (2011)

also argued the critical view of reinforcement of individual's existing beliefs and segregation based on interest in the Internet. Yet some research most recently criticizes these theories. For example, Elizabeth Doubois and Grant Blank point out the limitation of definitions and measurements of being in an echo chamber and criticize ignorance of the theory in the realistic context of a multiple media environment (see Dubois \& Blank 2018).

${ }^{21}$ Sports section, written by unknown author http://www.afpbb.com/articles/22912192?cx position=9 (accessed 28 June 2018).

22 Architecture section, written by unknown author

https://www.theguardian.com/artanddesign/2015/jul/17/go-kart-helmet-pottyalternative-uses-for-zaha-hadids-olympic-stadium (accessed 28 June 2018).

${ }^{23}$ http://world-architects.blogspot.com/2014/10/nationalstadiumsymposium.html (accessed 28 June 2018).

${ }^{24}$ https://iwj.co.jp/wj/open/archives/255542 (accessed 28 June 2018).

25 https://logmi.jp/63841 (accessed 28 June 2018).

26 Crozier explains, 'shame' is caused by negative self-evaluation or failure to meet ideal self-goals, and 'embarrassment' involves a matter of social evaluation, rather than self-evaluation (Crozer 2014:270).

27 Becoming a global brand is always accompanied by its paradoxical nature.

'Although at a certain stage in its life the brand name may function as a "strict form of designation,' it is only when it loses this function that it become brand "in the full sense of the world"' (Kapferer, 1992:115 cited in Frow, 202:64). For example, 'the nonsense word, "kodak" become a semantic matrix, not the name of a range of products, but the auratic source of their meaning and identity' (Frow 2002:64). This leads a 'signature-effect' which 'stands as metonyms of an originating author or artist' (Frow 2002:71).

28 There are many critical views about Kuma's victory, since Japanese construction industry has been dominated by a few giant construction companies who have capacity to complete mega architectural projects. The second competition required short construction time and cost-down. This only makes it possible to deploy design-built systems in which an architect and construction company work together as a team. Architects have to negotiate 
and compromise with strong construction companies which retain advanced architectural technologies and rich resources.

${ }^{29}$ Kengo Kuma 'Profile' in Kengo Kuma and associates

http://kkaa.co.jp/about/kengokuma/ (Accessed 15 April 2018). 


\section{References}

Anderson, Benedict. 1991. (Revised) Imagined Communities: Reflections on the Origin and Spread of Nationalism. New York: Verso.

Bourdieu, Pierre 1986. Distinction: A Social Critique of the Judgement of Taste. London: Routledge.

Crozier, Walter Raymond. 2014. Differentiating Shame from Embarrassment, emotion review Vol6 (3): 269-276.

De Cock, Christian, Volkmann, Christina. 2007. The Bauhaus and the Business School: Exploring Analogies, Resisting Imitation, Management Learning 38(4):389-403.

Dubios, Elizabeth \& Blank, Grant. 2018. The Echo Chamber is Overstated: the Moderating Effect of Political Interest and Diverse Media, Information, Communication \& Society 21(5): 729-745.

Featherstone, Mike. 2007. (second edition) Consumer Culture and Postmodernism. London: Sage Publications.

Foster, Hal. 2013. The Art-Architecture Complex. New York: Verso.

Frow, John. 2002. Signature and Brand in J. Collins (Ed.), High-Pop: Making Culture into Public Entertainment: 56-74.

Holly, Black. 2016. 'When Architecture Met Fashion in the Hands of Zaha Hadid', AnOther http://www.anothermag.com/fashion-beauty/9329/when-architecturemet-fashion-in-the-hands-of-zaha-hadid (accessed 31 March 2018).

Horn, John. 2011. Architects, Stadia and Sport Spectacles: Notes on the Role of Architects in the Building of Sport Stadia and Making of World-Class Cities. International Review for the Sociology of Sport 46(2): 205-227. 
Kaika, Maria. 2011. Autistic Architecture: the Fall of the Icon and the Rise of the Serial Object of Architecture. Society and Space (29): 968-992.

Kang, Jaeho and Traganou, Jilly. 2011. The Beijing National Stadium as Mediaspace. Design and Culture 3(2): 145-163.

Kennedy, Victoria. 2017 'Frank Gehry: Artist and Architect', Canvas, https://canvas.saatchiart.com/art/art-history-101/frank-gehry-artist-andarchitect (access 29 March 2018).

Larson, Magali Sarfatti. 1994. Architectural Competitions as Discursive Events. Theory and Society 23(4): 469-504.

Lash, Scott and Urry, John. 1994. Economics Sings and Space. London: Sage

McNeill, Donald. 2009. The Global Architect Firms, Fame and Urban Form. London: Routledge.

Lin, Zhongie. 2010. Kenzo Tange and the Metabolist Movement: Urban Utopias of Modern Japan. London: Routledge.

Maki, Fumio. 2014. Mondai no Konpon ha Purogramu ni aru (The fundamental problem could be found in the procedure of the competition programme) (ed.) Maki, Fumio and Hidetoshi Ono 'Shin Kokuritsu Kyougijyo, Nani ga Mondaika (New National Stadium, What is the problem?)'. Tokyo: Heibohsha.

McCurry, Justin. 2015 'Tokyo split over Zaha Hadid's 'gigantic white elephant' Olympic stadium' in the Guadian, 17 Jan.

https://www.theguardian.com/world/2015/jan/17/tokyo-denounce-zaha-hadidolympic-stadium (Accessed 12 April 2018).

Miah, Andy et. al. 2008. 'We Are The Media: Non-Accredited Media \& Citizen Journalists at the Olympic Games'. in Price, M. \& Dayan, D. (Ed.), Owning the Olympics: Narratives of the New China, Michigan: University of Michigan Press. 
Moore, Rowan. 2017. 'The Bilbao Effect: How Frank Gehry's Guggenheim Started a Global Graze', The Guardian.

https://www.theguardian.com/artanddesign/2017/oct/01/bilbao-effect-frankgehry-guggenheim-global-craze (access 29 March 2018).

Morby, Alice. 2018. 'Rem Koolhaas, Konstantin Grcic and Bouroullec Brothers All create Designs for Prada', de zeen.

https://www.dezeen.com/2018/01/15/ronan-erwan-bouroullec-konstantingrcic-rem-koolhaas-herzog-de-meuron-garments-prada-autumn-wintermenswear-fashion/ (accesed 31 March)

Nagashima, Kouichi. 2014. Rondon Orinpikku Shisetukeikaku, Sekkei no Jirei ni Furete (Considering the case of London Olympic facilities construction plan), (ed.) Maki, Fumio and Hidetoshi Ono 'Shin Kokuritsu Kyougijyo, Nani ga Mondaika (New National Stadium, What is the problem?)'. Tokyo: Heibohsha.

Nye, Joseph. 2005. (New Edition) Soft Power: The Means To Success in World Politics. Cambridge, MA:PublicAffairs.

Pariser, Eli. 2011. The filter bubble: What the Internet is hiding from you. New York: Penguin Press.

Sklair, Leslie. 2006. Iconic Architecture and Capitalist Globalization. City 10(1):21-47.

Sklair, Leslie. 2010. Iconic Architecture and the Culture-ideology of Consumarisum, Theory Culture \& Society 27(5):135-159.

Sunstein, Cass. 2001. 'The Daily We', Is the Internet Really a Blessing for Democracy?" in Boston Review, http://bostonreview.net/cass-sunsteininternet-democracy-daily-we (accessed 31 March 2018). 
Sunstein, Cass. 2007. Republic.com 2.0. First Edit. Princeton: Princeton University Press.

Tamari, Tomoko. 2014. Metabolism: Utopian Urbanism and the Japanese Modern Architecture Movement' in Special Section on Global Public Life, Theory Culture \& Society 31 (7-8) 201-225.

Tim Jeremy. 2009. Architecture Depends, Cambridge, MS: Massachusetts Institute of Technology (MIT).

\section{Image sources}

Figure 1 Zaha Hadid x Melissa (c) Melissa

http://www.anothermag.com/fashion-beauty/9329/when-architecture-metfashion-in-the-hands-of-zaha-hadid (accessed 29 June 2018)

Figure 2 Zaha Hadid x Louis Vuitton (c) Louis Vuitton

http://www.anothermag.com/fashion-beauty/9329/when-architecture-metfashion-in-the-hands-of-zaha-hadid (accessed 29 June 2018)

Figure 3: Zaha Hadid's revised design of the Tokyo Olympic Stadium https://skyrisecities.com/news/2015/12/kengo-kuma-and-toyo-ito-revealtokyo-olympic-stadium-designs (accessed 29 July 2018).

Figure 4 London Aquatic Centre designed by Zaha Hadid Architects https://nickrileyarchitect.com/tag/the-aquatics-centre/ (accessed 29 July 2018).

Figure 5 Al Wakrah Stadium designed by Zaha Hadid Architects http://www.stadiumquide.com/al-wakrah-stadium/ (accessed 29 June 2018). 